\title{
Polyvinylbenzyl Tris-Aminodicarboxylate Microspheres for the Optical Sensing of $\mathrm{Cu}^{2+}$ Ions
}

\author{
Ziad M. Shakhsher ${ }^{1}$, Ibrahim Abu Shqair ${ }^{2}$, Hanin R. Qasim² ${ }^{2}$ Imad Odeh ${ }^{1 *}$ \\ ${ }^{1}$ Department of Chemistry and Chemical Technology, Al-Quds University, Jerusalem, Palestine \\ ${ }^{2}$ Department of Chemistry, An-Najah National University, Nablus, Palestine \\ Email: odehim@science.alquds.edu
}

Received November 30, 2013; revised December 29, 2013; accepted January 8, 2014

Copyright (c) 2014 Ziad M. Shakhsher et al. This is an open access article distributed under the Creative Commons Attribution License, which permits unrestricted use, distribution, and reproduction in any medium, provided the original work is properly cited. In accordance of the Creative Commons Attribution License all Copyrights @ 2014 are reserved for SCIRP and the owner of the intellectual property Ziad M. Shakhsher et al. All Copyright (C) 2014 are guarded by law and by SCIRP as a guardian.

\begin{abstract}
In this work, a tris(2-aminoethyl)aminodicaboxylate functionality was substituted for the chloride of polyvinylbenzyl chloride (PVBC) which was lightly cross-linked (2\%) with divinyl benzene. The resulting derivatized polymer microspheres were embedded in a hydrogel matrix of poly vinyl alcohol cross-linked with glutaraldehyde to produce a sensing membrane. The latter responded selectively to $\mathrm{Cu}^{2+}$ solutions of different concentration ranges $\left(1 \times 10^{-4} \mathrm{M}\right.$ to $\left.1 \times 10^{-6} \mathrm{M}\right)$. The response is based on the interaction between the metal cations and the negatively charged deprotonated dicarboxylate functional group, which led to neutralization of the charges. As a result, an increase in the turbidity of the sensing membrane occurred which is attributed to a change in the refractive index of the derivatized polymer microspheres relative to that of the hydrogel. The change in the turbidity of the sensing membrane was measured as absorbance using a conventional spectrophotometer. It was found that $\mathrm{Cu}^{2+}$ ions bind to the aminodicarboxylated-polymer with a formation constant, $\mathrm{K}_{\mathrm{f}}$, of $1 \times 10^{5} \mathrm{M}^{-1}$. SEM, Eds and IR analyses were performed on the aminodicarboxylated microspheres and their $\mathrm{Cu}^{2+}$ complex.
\end{abstract}

\section{KEYWORDS}

Tris(2-aminoethyl)aminodicarboxylate-Polymer; Optical Sensing; Refractive Index; SEM; Eds

\section{Introduction}

Heavy metal ions such as Mercury, Cadmium, Lead, Nickel and Copper discharged into water by natural and anthropogenic sources are causing environmental and biological problems and have become a global concern [1-3]. Although a variety of methods are available for their removal, fast and effective means for their detection are still needed [4-17]. In a recent study, selective determination of copper ions in aqueous solutions utilizing aminodicarboxylic acid for the chelation of copper (II) ions was reported. Lin et al. modified the surface of an evanescent wave element by depositing a thin layer of the ligand producing a sensitive and selective infra-red chemical sensor capable of detecting micro molar concentrations of $\mathrm{Cu}^{2+}$ ions within a time frame of 20 minutes [4]. We believe that using an optical chemical sensor

*Corresponding author. would improve significantly the detection limit and produce a faster response time. A variety of analytes were detected using optical sensing elements developed by our group [11-14]. Such a sensor is based on polymer swellings that result from complexation of a specific analyte with a specific functional group located on the polymer microspheres. The latter form a sensing element upon entrapping them in polyvinyl alcohol cross-linked with glutaraldehyde. The resulting sensing element demonstrated excellent resistance to photodegradation and indicator dye leaching as well as to mechanical degradation. In addition, these sensors were effective at very low concentration (down to $1 \mu \mathrm{M}$ ) and responded within a very short time (95\% response in 5 minutes) and were insensitive to $\mathrm{pH}$ changes [11,14].

In a previous work, we were able to develop an optical chemical sensing element based on polymer swelling, in which polyvinylbenzyl chloride (PVBC) lightly cross- 
linked with divinylbenzene as microspheres were derivatized with dicarboxylate and embedded in a hydrogel membrane to form a sensing element [12,13]. This kind of sensing element had some limitations, particularly its lack of selectivity. It responded to varying $\mathrm{pH}$ values, and also to $\mathrm{Ca}^{2+}, \mathrm{Ni}^{2+}, \mathrm{Zn}^{2+}$, and $\mathrm{Cd}^{2+}$ ions. To improve the selectivity, we selected a functionality that is chemically similar to that of ethylenediamine tetraacetic acid (EDTA), a common chelating agent for metal ions but known to form highly thermodynamic chelates with $\mathrm{Cu}^{2+}$ ions [4]. In this study, polyvinylbenzyl tris(2-aminoethyl)aminodicarboxylate microspheres were synthesized starting from PVBC cross-linked with divinylbenzene (2\%). The resulting derivatized microspheres were embedded in a hydrogel matrix of polyvinylalcohol crosslinked with glutaraldehyde to form an optical sensing element. The response to $\mathrm{Cu}^{2+}$ ions as change in the turbidity of the sensing membrane was measured as absorbance using a conventional spectrophotometer.

\section{Experimental}

\subsection{Reagents}

All chemical reagents used were of analytical grade. N,N-dimethylformamide(DMF), tris(2-aminoethyl)amine (TAA), polyvinyl alcohol(PVA), glutaraldehyde $8 \%$ by weight, were purchased from Sigma-Aldrich. Bromooacetic acid was obtained from Riedel. All solutions were prepared in deionized distilled water. Polyvinylbenzyl chloride (PVBC) lightly cross-linked with divinylbenzene ( $2 \%$ mole) microspheres of $1-3 \mu \mathrm{M}$ diameter were supplied by the Chemistry Department at the University of New Hampshire (USA).

\subsection{Instruments}

Absorption measurements were performed on Shimadzu UV-VIS-NIR Scanning spectrophotometer (Shimadzu UV-3101PC). A Fourier transform infrared spectrophotometer (Testscan Shimadzu FT-IR 8000 series) was used to obtain IR-Spectra. The $\mathrm{pH}$ measurements were recorded on a Jenway pH meter (3510). SEM and Eds analyses of the adsorbent before and after complexation with copper (II) ions were performed by mounting the samples on metal stubs and coating them with gold (Polaron Spatter coater). The microphotographs were recorded using a scanning electron microscope JEOL model, JSM-5410 LV (available at the microscopy lab at the faculty of agriculture, food and environmental quality Sciences, The Hebrew University). The images were taken with an accelerating voltage of $25 \mathrm{kV}$, at high vacuum (HV mode) and secondary electron image (SEI). The analysis was done using Oxford systems-Liquid Nitrogen cooled solid state Energy Dispersive Spectrometer detector and link ISIS software.

\subsection{Synthesis of the Tris(2-aminoethyl)amino (TAA) Polymer}

One gram (0.0066 mole) of PVBC was stirred in $12 \mathrm{ml}$ DMF for two hours then $4 \mathrm{ml}$ of the tris-amine (TAA, 4 equivalents) were added and the reaction was stirred for one week. The DMF and excess tris-amine were then removed by a series of centrifugations, and decantations. Then the polymer was washed several times (3 times) with distilled water. The water was also removed by a series of centrifugations, and decantations. The polymer was allowed to dry in air. The mass of tris-amine polymer obtained was $1.384 \mathrm{~g}$.

\subsection{Synthesis of the Tris(2-aminoethyl)aminodicarboxylate (TAAD) Polymer}

One gram of the tris-amino polymer was added to a solution of $2 \mathrm{~g}$ of Bromoacetic acid in $25 \mathrm{ml} 3 \mathrm{M} \mathrm{NaOH}$ and the reaction was allowed to stir at room temperature for one week. The reaction was then stopped and the polymer collected by suction filtration. The mass of the polymer obtained was $1.160 \mathrm{~g}$.

\subsection{Preparation of the Optical Sensing System}

The TAAD derivatized polymer microspheres $(10 \mathrm{mg})$ were soaked in a few drops of DMF for a few minutes, then $1 \mathrm{ml}$ of 5\% aqueous PVA solution was added and the mixture was placed in a sonicator until the polymer microspheres were dispersed and the mixture became uniform. Then, the PVA/TAAD mixture was crosslinked by mixing with $80 \mu \mathrm{l}$ of $8 \%$ aqueous glutaraldehyde, followed by $80 \mu \mathrm{l}$ of $3 \mathrm{M} \mathrm{HCl}$ (aq). A few drops of the resulting mixture were immediately transferred and spread on the inner clear side wall of a plastic cuvette. The sensing membrane was allowed to formulate and stick in position. The resulting sensing element was washed with and stored in distilled water. The cuvette with the sensing element stuck on its inner sidewall was secured in the cell holder of a conventional spectrophotometer, so that the membrane was positioned in the path of the light beam (Figure 1).

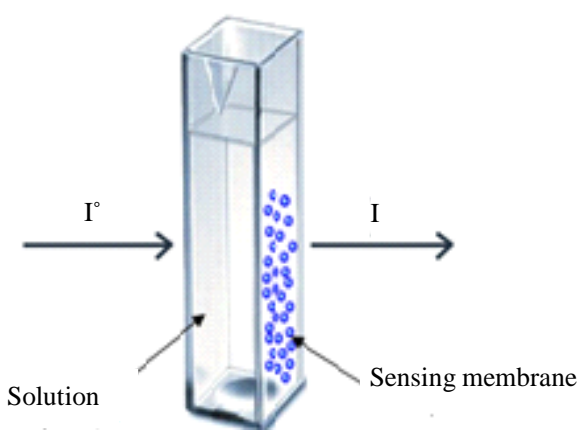

Figure 1. Diagram of optical sensing system. 


\subsection{Optical Measurements}

The solution in the cuvette was changed using a disposable pipette, starting with the lower concentrations of analyte and proceeding to the higher ones. The change in turbidity of the sensing element as a function of analyte concentration was measured as absorbance at $800 \mathrm{~nm}$. The response of the sensing element to $\mathrm{pH}$ was obtained starting with lower $\mathrm{pH}$ and proceeding to the higher ones with an interval of 10 minutes between each spectrum run. The reproducibility of the sensor response was evaluated by cycling between blank and $0.001 \mathrm{M} \mathrm{Cu}^{2+}$ ions solution several times. Between measurements, the sensing element was eluted by a saturated solution of EDTA and then washed extensively with distilled water until obtaining the blank reading. The response time of the sensing element towards $0.001 \mathrm{M}$ of $\mathrm{Cu}^{2+}$ ions was obtained by measuring the change in absorbance with time, until steady state is reached.

\section{Results and Discussion}

\subsection{Characterization of the Ligand- $\mathrm{Cu}^{2+}$ Complex}

The variation in the appearance of the IR specta of the tris(2-aminoethyl)aminodicaboxylate polymer-Cu ${ }^{2+}$ complex from that of the tris(2-aminoethyl)aminodicaboxylate polymer is indicative of the complex formation. Thus, the carboxylate characteristic bands for the asymmetric and symmetric stretching frequencies appearing at ca. 1594 and 1438 became less intense [4]. Also two new bands are observed at ca. 1063 and $532 \mathrm{~cm}^{-1}$ which are attributed to the $\mathrm{C}-\mathrm{O}$ and $\mathrm{N}-\mathrm{Cu}$ stretching frequencies [18] (Figure 2). SEM analysis showed an increase in the average size of the polymer microspheres possibly due to adsorption of copper ions on the polymer surface in addition to chelation with the aminodicarboxylate functionality (Figure 3). Elemental analysis of the surface of the polymer at three different points using Energy Dispersive Spectrometry (EDS) showed beyond doubt the presence of nitrogen, oxygen and copper, the three-element component of the aminodicarboxylate functionality (Table 1).

\subsection{Sensing Element Evaluation}

As the sensing element was examined with different buffer solutions ( $\mathrm{pH} 5$ - 12), insignificant changes in absorbance were observed. This is probably related to the fact that the tris-aminodicaboxylate polymer contains both basic amino groups and acidic carboxyl groups. The nitrogen and the oxygen are both protonated at low $\mathrm{pH}$. Thus, the positive charges on nitrogen repel each other causing the polymer to be in a swollen state. As the $\mathrm{pH}$ is raised, the oxygen on the carboxylic group becomes de-

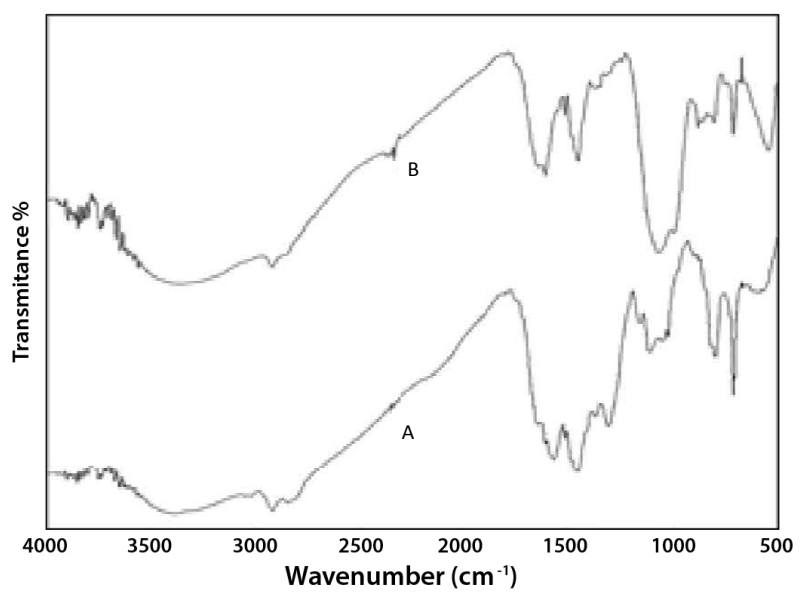

Figure 2. FTIR spectra: (A) Tris amino dicarboxylate (TAAD) polymer; (B) Tris amino carboxylate- $\mathrm{Cu}^{2+}$ complex.

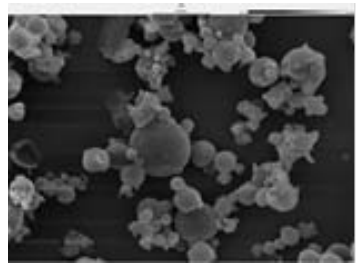

1

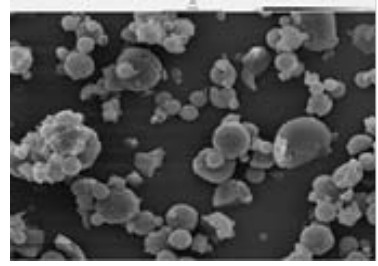

2

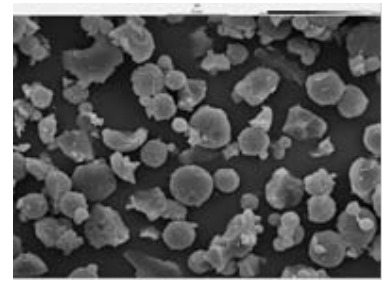

3

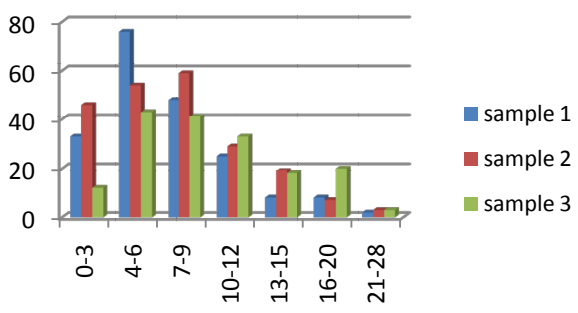

Size distribution of microspheres $(\mu \mathrm{m})$

Figure 3. SEM images of (1) Tris(2-aminoethyl)amino (TAA) polymer; (2) Tris(2-aminoethyl)aminodicaboxylate (TAAD) polymer; (3) Tris(2-aminoethyl)aminocaboxylate polymer$\mathrm{Cu}^{2+}$ complex and the size distribution of the polymer microspheres.

protonated. The negative charges repel each other causing the polymer to stay in a swollen state. This behavior does not lead to any significant change in refractive index, and thus no detectable change in absorbance was recorded (Figure 4).

The tris-aminodicarboxylate polymer showed no response towards tested heavy metal cations $\left(\mathrm{Co}^{2+}, \mathrm{Ni}^{2+}\right.$, 
Table 1. Elemental analysis of tris(2-aminoethyl)aminodicaboxylate polymer- $\mathrm{Cu}^{2+}$ complex.

\begin{tabular}{cccc}
\hline & \multicolumn{3}{c}{ Weight \% } \\
\cline { 2 - 4 } Element & pt1 & pt2 & pt3 \\
\hline C-K & 27.57 & 51.01 & 50.01 \\
N-K & 10.53 & 16.66 & 17.59 \\
O-K & 46.71 & 21.14 & 23.72 \\
F-K & & & 1.30 \\
Na-K & 1.02 & & \\
Al-K & 0.45 & 0.35 & 0.33 \\
Si-K & 12.04 & 2.27 & 2.60 \\
Cl-K & 0.16 & 1.13 & 0.40 \\
K-K & 0.13 & & \\
Cu-K & 0.89 & 4.20 & 2.94 \\
Ag-L & 0.50 & 3.24 & 1.11 \\
\hline
\end{tabular}

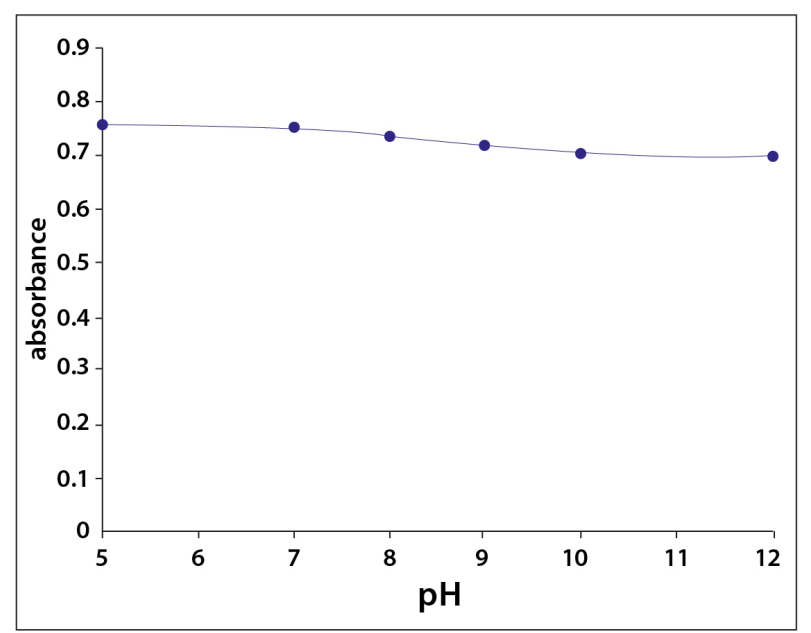

Figure 4. Turbidity absorbance of the sensing element at different pHs.

$\mathrm{Hg}^{2+}$ ) at all concentrations (Figure 5). On the other hand, it demonstrated a significant affinity towards $\mathrm{Cu}^{2+}$ ions in agreement with previous reports [4] (Figures 6 and 7).

The response of the sensing membrane to $\mathrm{Cu}^{2+}$ ions is based on the interaction between these ions and the aminodicarboxylate functional group situated on the polymer microspheres.

As a result, an increase in the turbidity of the sensing element occurred due to a change in the refractive index of the derivatized polymer microspheres relative to that of the hydrogel. Thus, as the concentration of the $\mathrm{Cu}^{2+}$ solution was varied between $1 \times 10^{-6} \mathrm{M}$ and $1 \times 10^{-4} \mathrm{M}$ an increase in absorbance was observed. The sensing element demonstrated good reproducibility in response towards $\mathrm{Cu}^{2+}$ ions.

The formation constant $\left(\mathrm{K}_{\mathrm{f}}\right)$ of binding of $\mathrm{Cu}^{2+}$ ions with the tris-aminodicarboxylate-polymer was obtained

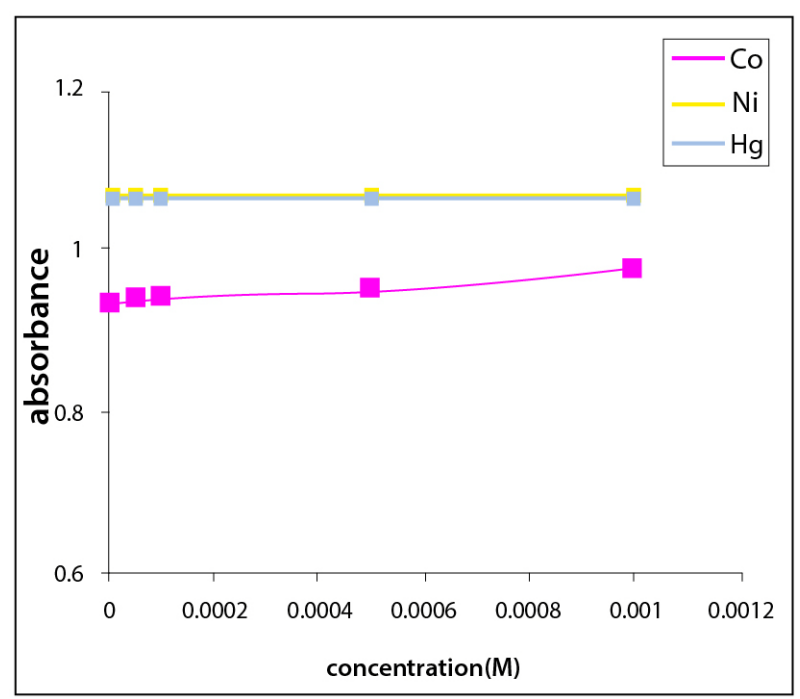

Figure 5. Turbidity absorbance of sensing element vs concentration of $\mathrm{Co}^{2+}, \mathrm{Ni}^{2+}$ and $\mathrm{Hg}^{2+}$ ions.

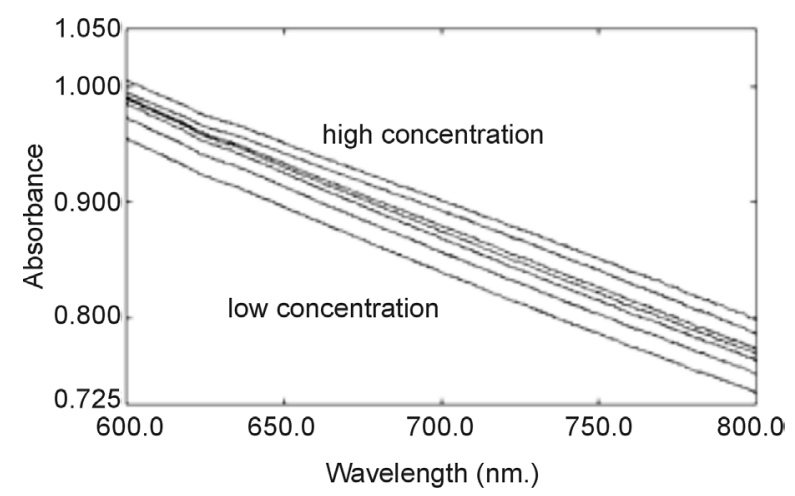

Figure 6. Variation of absorbance of sensing element vs wavelength of different $\mathrm{Cu}^{2+}$ concentration $\left(1 \times 10^{-6}\right.$ to $1 \times$ $\left.10^{-4}\right)$.

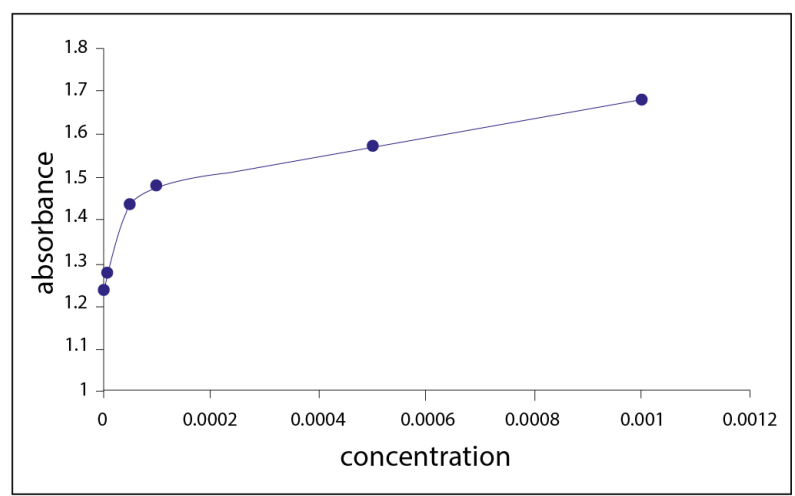

Figure 7. Turbidity absorbance of sensing element vs concentration of $\mathrm{Cu}^{2+}$ ions.

from the plot of Figure 7. As the amounts of the free and the bonded ligand will be equal at the point half-way to the maximum response, $\mathrm{K}_{\mathrm{f}}$ is equal to $1 /\left[\mathrm{Cu}^{2+}\right]$, where the concentration of $\mathrm{Cu}^{2+}$ ion is $1 \times 10^{-5} \mathrm{M}$. Thus, the forma- 
tion constant $\left(\mathrm{K}_{\mathrm{f}}\right)$ is calculated to be $1 \times 10^{5} \mathrm{M}^{-1}$. This result ensures the high selectivity of the prepared sensing element toward $\mathrm{Cu}^{2+}$ ion.

The response of the sensing element was examined towards $\mathrm{Cu}^{2+}(0.001 \mathrm{M})$, at different $\mathrm{pH}$ buffered solutions (pH 2 - 9). We detected a small change in absorbance up to about $\mathrm{pH}$ 7. But, above that, significant increases in absorbance were observed. This is probably due to an increase in the fraction of the deprotonated functional groups that resulted in an enhancement of the complex formation between ligand and $\mathrm{Cu}^{2+}$ ions (Figure 8).

The response time of the sensing membrane toward $\mathrm{Cu}^{2+}$ ions was obtained by measuring the change in absorbance of a solution of $1 \times 10^{-3} \mathrm{M} \mathrm{Cu}^{2+}$ ions at $800 \mathrm{~nm}$ versus time. The absorbance increased sharply up to about 5 minutes and then leveled off (Figure 9). This pattern in the response time may be attributed to the increase in the thickness of the shrinking outer layer of the microsphere surface, which resulted in a significant reduction in the rate of diffusion of $\mathrm{Cu}^{2+}$ ions and water through it.

In agreement with previously reported results, the trisaminodicarboxylate polymer microspheres showed no response toward alkali and alkaline earth metal cations, such as $\mathrm{Ca}^{2+}, \mathrm{Mg}^{2+}, \mathrm{K}^{+}$, and $\mathrm{Na}^{+}$.

Thus, the presence of these metal cations will not be expected to affect the optical properties of the sensing membrane (Figure 10).

\section{Conclusion}

In this work, a tris-aminodicarboxylate functional group was substituted for the chloride of PVBC which was cross-linked with divinyl benzene (2\%). The resulting derivatized microspheres were entrapped in a hydrogel membrane (PVA) to produce a sensing element. The resulting sensor responded selectively to $\mathrm{Cu}^{2+}$ ions at concentrations ranging between $1 \times 10^{-6} \mathrm{M}$ and $1 \times 10^{-4} \mathrm{M}$,

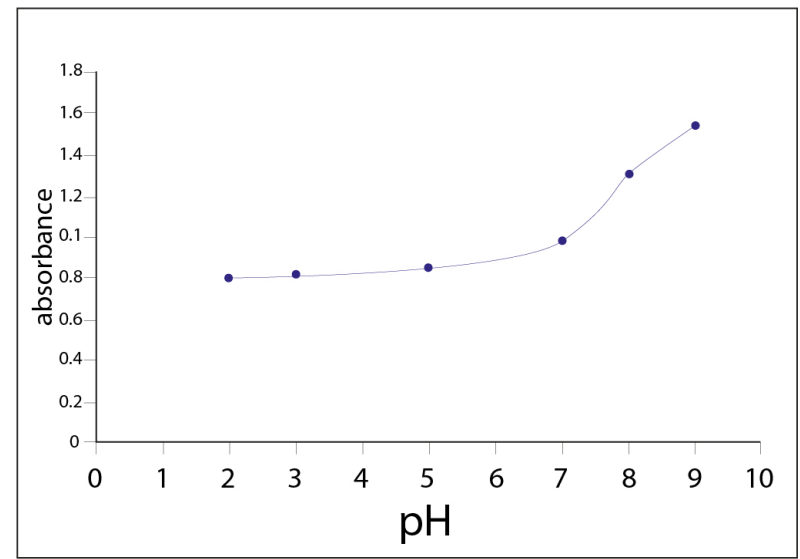

Figure 8. Turbidity absorbance of the sensing element for $0.001 \mathrm{M} \mathrm{Cu}^{2+}$ at different pHs.

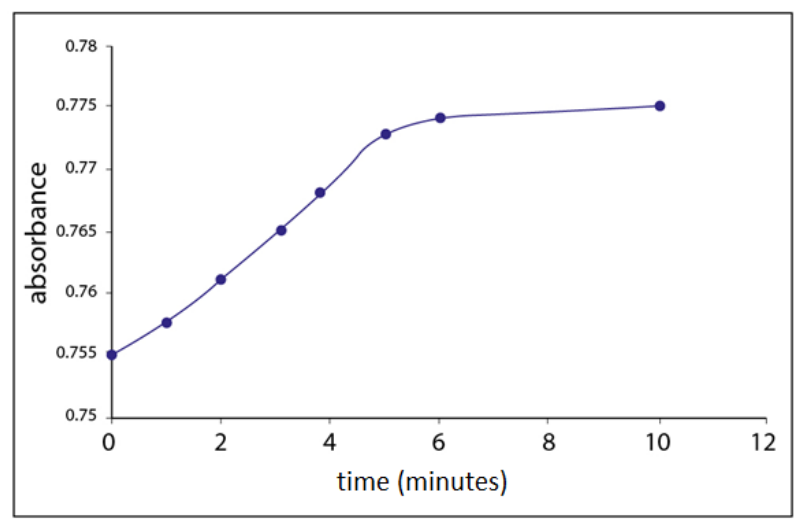

Figure 9. Response time of the sensing element towards $\mathrm{Cu}^{2+}$ ions.

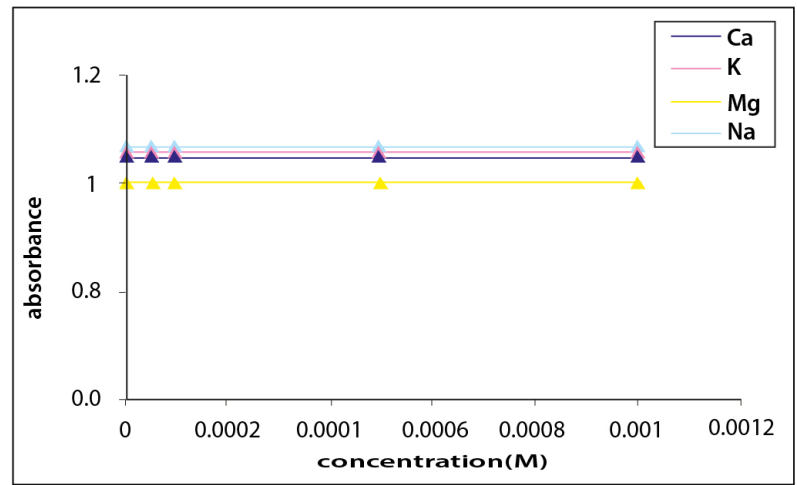

Figure 10. Turbidity absorbance of sensing element vs concentration of alkali and alkaline earth metal ions.

with a formation constant $\left(\mathrm{K}_{\mathrm{f}}\right)$ of $1 \times 10^{5} \mathrm{M}^{-1}$. In addition, no significant response to other metal ions, especially alkali and alkaline earth metal and some heavy metal ions $\left(\mathrm{Co}^{2+}, \mathrm{Ni}^{2+}, \mathrm{Hg}^{2+}\right)$ was detected, regardless of their concentrations.

\section{Acknowledgements}

We are grateful to Professor W. R. Seitz and his research group, at the University of New Hampshire (USA) for their fruitful comments and for supplying us with the polyvinylbenzyl chloride microspheres. We are also grateful to the staff at the department of chemistry of An-Najah National University (PA), for their technical assistance.

\section{REFERENCES}

[1] J. Moore, "Inorganic Contaminants of Surface Water," Springer-Verlag, New York, 1991. http://dx.doi.org/10.1007/978-1-4612-3004-5

[2] B. Carson, H. Ellis and J. MacCann, "Toxicology and Biological Monitoring of Metals in Humans,” Lewis Publishers, Chelsea, 1987.

[3] D. Barceloux, “Copper,” Journal of Toxicology-Clinical 
Toxicology Vol. 37, No. 2, 1999, pp. 217-230. http://dx.doi.org/10.1081/CLT-100102421

[4] H. C. Lin, Y. H. Chou and J. Yang, "Development of an Amino Carboxylic Acid-Modified Infrared Chemical Sensor for Selective Determination of Copper Ions in Aqueous Solutions,” Analytica Chimica Acta, Vol. 611, No. 1, 2008, pp. 89-96. http://dx.doi.org/10.1016/j.aca.2008.01.069

[5] X. Zhang, X. Kong, W. Fan and X. Du, "Iminodiacetic Acid-Functionalized Gold Nanoparticles for Optical Sensing of Myoglobin via $\mathrm{Cu}^{2+}$ Coordination," Langmuir, Vol. 27, No. 10, 2011, pp. 6504-6510. http://dx.doi.org/10.1021/la200177e

[6] A. Richter, G. Paschew, S. Klatt, J. Leinig, K. F. Arndt and H. J. P. Adler, "Review on Hydrogel-Based pH Sensors and Microsensors,” Sensors, Vol. 8, No. 1, 2008, pp. 561-581. http://dx.doi.org/10.3390/s8010561

[7] P. C. A. Jeronimo, A. N. Araujo, M. Conceicao and B. S. M. Montenegro, "Optical Sensors and Biosensors Based on Sol-Gel Films,” Talanta, Vol. 72, No. 1, 2007, pp. 1327. http://dx.doi.org/10.1016/j.talanta.2006.09.029

[8] J. Y. Haras, D. Silvio, R. Rodrigues and M. Negri, “Chelating Electrodes as Taste Sensor for the Trace Assessment of Metal Ions," Sensors and Actuators, Vol. 145, No. 2, 2010, pp. 726-733. http://dx.doi.org/10.1016/j.snb.2010.01.027

[9] W. R. Seitz, M. T. Rooney, E. W. Miele, H. Wang, N. Kaval, L. Zhang, S. Doherty, S. Milde and J. Lenda, "Derivatized Swellable Polymer Microspheres for Chemical Transduction," Analytica Chimica Acta, Vol. 400, No. 1-3, 1999, pp. 55-64. http://dx.doi.org/10.1016/S0003-2670(99)00608-X

[10] O. Oktar, P. Caglar and W. R. Seitz, "Chemical Modulation of Themosensitive Poly(N-isopropyl acryamide) Microsphere Swelling: A New Strategy for Chemical Sensing," Sensors and Actuators B, Vol. 104, No. 2, 2005, pp. 179-185. http://dx.doi.org/10.1016/j.snb.2004.04.033

[11] Z. Shakhasher, I. Odeh, I. Rajabi and M. Khatib, "Optical Sensing Properties of Dithiocarbamate Functionalized Microspheres, Using a Polyvinyl Pyridine-Polyvinyl Ben- zyl Chloride Copolymer,” Sensors, Vol. 10, No. 10, 2010 , pp. 8953-8962.

http://dx.doi.org/10.3390/s101008953

[12] Z. Shakhasher, I. Odeh, S. Jabr and W. R. Seitz, “An Optical Chemical Sensor Based on Swellable Dicarboxylate Functionalized Polymer Microspheres for $\mathrm{pH}$ Copper and Calcium Determination," Microchimica Acta, Vol. 144, No. 1-3, 2004, pp. 147-153. http://dx.doi.org/10.1007/s00604-003-0077-2

[13] I. Odeh, Z. Shakhsher, S. Jaber, M. Khatib and F. Rimawi, "An Optical Sensor Based on Polyvinyl Benzyl Malonate Cross-Linked with Divinyl Benzene Dispersed in a Hydrogel Membrane for Detection of Some Heavy Metals," American Journal of Analytical Chemistry, Vol. 3, No. 4, 2012, pp. 283-287. http://dx.doi.org/10.4236/ajac.2012.34038

[14] I. Odeh, S. Siam, M. Khatib and Z. Shakhasher, “An Optical Chemical Sensor Based on Polymer Swelling and Shrinking Using Dithiocarbamate-Polymer Microspheres," Jordan Journal of Chemistry, Vol. 4, 2009, pp. 55-64.

[15] K. Liu and H. F. Ji, "Detection of $\mathrm{Pb}^{2+}$ Using a Hydrogel Swelling Micro Cantilever Sensor,” Analytical Sciences, Vol. 20, No. 1, 2004, pp. 9-11. http://dx.doi.org/10.2116/analsci.20.9

[16] J. H. Holtz and S. A. Asher, "Polymerized Colloidal Crystal Hydrogel Films as Intelligent Chemical Sensing Materials,” Nature, Vol. 389, No. 6653, 1997, pp. 829832. http://dx.doi.org/10.1038/39834

[17] W. Li, H. Zhao, P. R. Teasdal, R. John and S. Zhang, "Synthesis and Characterization of a PolyacrylamidePolyacrylic Acid Copolymer Hydrogel for Environmental Analysis of $\mathrm{Cu}$ and Cd," Reactive and Functional Polymers, Vol. 52, No. 1, 2002, pp. 31-41. http://dx.doi.org/10.1016/S1381-5148(02)00055-X

[18] M. Sonmez, "Synthesis and Characterization of Copper (II), Nickel (II), Cadmium (II), Cobalt (II), and Zinc (II) Complexes with 2-Benzoyl-3-hydroxy-1-naphthyl Amino-3-phenyl-2-propen-1-on," Turkish Journal of Chemistry, Vol. 25, 2001, pp. 181-185. 